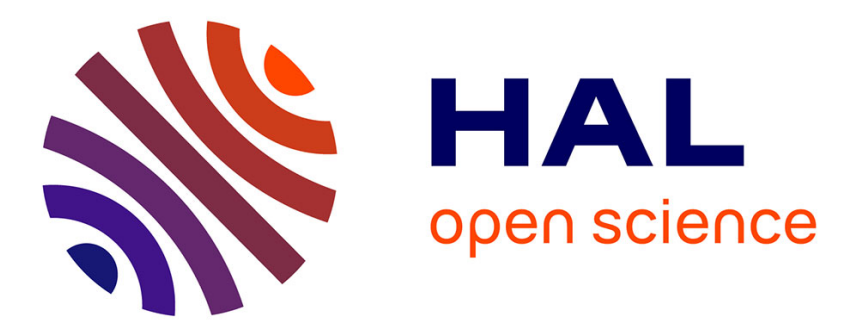

\title{
Research directions in eco-innovation: a French perspective
}

Flore Vallet, Benjamin Tyl, François Cluzel, Yann Leroy

\section{To cite this version:}

Flore Vallet, Benjamin Tyl, François Cluzel, Yann Leroy. Research directions in eco-innovation: a French perspective. International Journal on Interactive Design and Manufacturing, 2016, 10 (3), pp.309-318. 10.1007/s12008-016-0332-5 . hal-01446062

\section{HAL Id: hal-01446062 \\ https://hal.science/hal-01446062}

Submitted on 24 Feb 2020

HAL is a multi-disciplinary open access archive for the deposit and dissemination of scientific research documents, whether they are published or not. The documents may come from teaching and research institutions in France or abroad, or from public or private research centers.
L'archive ouverte pluridisciplinaire HAL, est destinée au dépôt et à la diffusion de documents scientifiques de niveau recherche, publiés ou non, émanant des établissements d'enseignement et de recherche français ou étrangers, des laboratoires publics ou privés. 


\title{
Research directions in eco-innovation: a French perspective
}

\author{
Flore Vallet ${ }^{1,2,3}(\bowtie)$, Benjamin Tyl ${ }^{4}$, François Cluzel $^{2}$ and Yann Leroy ${ }^{2}$ \\ ${ }^{1}$ Sorbonne universités, Université de Technologie de Compiègne, CNRS, UMR 7337, 60203 Compiègne cedex, France \\ ${ }^{2}$ Laboratoire Genie Industriel, CentraleSupélec, Université Paris-Saclay, 92290 Chatenay-Malabry, France \\ ${ }^{3}$ IRT SystemX, 91127 Palaiseau, France \\ ${ }^{4}$ APESA, Technopole IZARBEL, 64210 Bidart, France
}

Received: day month year / Revised: day month year / Accepted: day month year (automatically inserted by the publisher) (C) Tsinghua University Press and Springer-Verlag Berlin Heidelberg 2011

\begin{abstract}
The French network EcoSD (Eco-design of Sustainable Systems) has initiated collaborative research projects in order to foster collaborations between academic and industrial partners. Two projects concerning eco-innovation processes, methods and tools have been carried out between 2012 and 2014. This paper first offers a synthesis of the projects, and questions the new directions to feed research in eco-innovation for the forthcoming years. The first project concerned the perception of eco-innovation by companies. It aimed at defining the features and goals of eco-innovation compared to eco-design through a survey with 12 French industrial partners. Results confirm that eco-innovation still is an emerging topic and does not seem to be supported by any structured process. The second project made a focus on the stage of eco-evaluation and eco-selection of the most promising ideas. In order to understand the emergence of ideas with a high environmental potential, three groups of mixed academics and industrials were asked to test two methods involving mapping, selection, combination and environmental evaluation of ideas. Main results show that there is a large inter-group variability in the evaluation of the environmental potential of ideas. Lastly, three interlinked directions for research in eco-innovation are identified. The first direction deals with the eco-ideation phase, where appropriate stimulation mechanisms should be integrated to. The second direction deals with the environmental evaluation of ideas very early in the process. It is necessary to characterize the inputs and outputs from this phase, building a bridge towards a latter simplified environmental assessment. The last direction deals with the construction of an efficient eco-innovation process based on the two previous phases. The challenge is to reduce the gap between academia and industry, enabling companies to introduce an eco-innovation process into their current design process.
\end{abstract}

\section{KEYWORDS}

Eco-innovation, eco-design, environmental potential, idea selection.

\section{Introduction}

A clear interest for eco-innovation has been noticed in academia in the past few years [1]. Considering the environmental dimension is seen as one of the promising levers to achieve product innovation, notably through adaptation of the TRIZ method [2, 3]. In [3], the focus is made on coupling TRIZ tools 
with bionics in an interactive design perspective.

Research on eco-innovation has been performed to analyze its theoretical foundation [4], its various definitions $[5,6]$ but also how eco-innovation can be supported by business models $[7,8]$. In a design perspective, the different dimensions of an ecoinnovative product have been studied [9] and various tools have been developed, in several steps of the process from idea generation [10, 11, 12] to idea evaluation $[13,14]$ and idea maturation [15].

The European Commission has funded ecoinnovations programs for several years, 10 of which are reported in [16]. While some projects are sectorial with a dominant technological content (e.g. Biochem, Innowater, ReMake, EcoTroFood), others cover generic issues of research, methodology or dissemination of best practices (for instance EcoInnovera, InnovationSeeds, Ecoweb...). More specifically, in France, Research and Development programs on eco-innovation have strongly increased. From 2010, PhD theses have been performed in both academic and industrial context, with SMEs and major companies (for example [15, 17, 18, 19]. Moreover, French policy now gives importance to eco-innovation through the environmental legislation package 'Grenelle de l'Environnement' which promotes a range of strategies related to eco-innovation issues.

In this context, the French network EcoSD (Ecodesign of Sustainable Systems) funded two Collaborative Research Projects (CRP) on ecoinnovation mixing industrials, academics, consultants, as well as one technological centre. These CRP were concluded in 2015 by a seminar on this thematic to open discussions and draw new opportunities.

The expected outcomes of interactive design and engineering may be new behavioral models, new virtual systems or prototypes for improving decision-making in product design and manufacturing. Yet, before implementing a virtual exploration of solution spaces, it is worth taking a more global, and also process-based, outlook.

This paper aims to elaborate on a way to develop eco-innovation practices in engineering. It outlines the pragmatic research process on eco-innovation in order to lead future studies for both academics and industrials.

Section 2 gives an overview of the dimensions, scope and drivers associated with the eco-innovation concept and practice. After introducing the articulation of research works conducted with partners of the national EcoSD network (section 3), section 4 reports on the main findings confronted to recent literature findings. Trends and perspectives for eco-innovation research are formulated at a national, then international level. Final conclusions are delivered in section 6 .

\section{Background}

\subsection{The concept of eco-innovation}

Diaz-Garcia et al. summarized 8 different definitions of eco-innovation appearing in key studies between 1996 and 2013 [1]. It concerns a new product or service which significantly reduce the environmental impacts all along its life cycle. Since the first definition was given by Fussler and James [20], the concept has drifted from a product/service to a potentially more organizational focus; from a purely environmental to a mixed environmental, social and even institutional contribution [21]. Mathieu et al. add that eco-innovation creates positive externalities on one or several dimensions of sustainable development [21].

In O'Hare and Mc Aloone [22], the concept of ecoinnovation is discussed with regard to three anchoring domains: engineering design; strategy and management; environmental science.

The recent contribution of the UNEP guide emphasizes the importance of the business model issue associated with eco-innovation: "Eco innovation is the development and application of a business model, shaped by a new business strategy that incorporates sustainability throughout all business operations based on life cycle thinking and in cooperation with partners across the value chain." [23].

2.2. Typologies of eco-innovations

Even if eco-innovation is more and more studied in literature, a strong shortcoming remains on the identification of an eco-innovation and on the differences with a "traditional" innovation. 
In line with innovation, Rennings shows that ecoinnovation can be technological, organizational, social or institutional, and developed by a wide range of stakeholders, from companies to NGOs [24]. Nevertheless, Hellstrom [9] underlines that the systemic nature of eco-innovation is important to understand what it can be. Therefore, ecoinnovation must be supported by a corresponding evolution of social arrangements and institutional structures [9].

For Hojnik and Ruzzier [4], eco-innovation may be distinguished from innovation because of its interdisciplinary approach, between innovation and environmental economics, whereas Roscoe et al. [25] emphasize the specificities of the supply network to develop and disseminate eco-innovation. Moreover, eco-innovation seems to require more external knowledge than traditional innovation [4].

Diaz-Garcia et al. [1] stress that the focus of ecoinnovation is either on the effect (i.e. the contribution to environmental improvement), or on the motivation (the goal of sustainable development) or both. For Mathieu et al. [21], eco-innovation may be intentional or not, as it is the contribution (and not the objective) that has to be relevant to sustainable development. This means that ecoinnovation may be appreciated ex post, after launch to market. However, for Hansen et al. [26], one may distinguish product innovations (after the market launch) from product innovation projects (concepts or ideas).

From a product design point of view, O'Hare defines an eco-innovative product as 'one that is significantly less environmentally harmful than the use of relevant alternative products.' [10]. A wide diversity of both products and processes can be considered as eco-innovations, from incremental, drop-in innovations to systemic changes [6]. However Hellstrom [9] underlines that radical ecoinnovation products are achieved when both technology and systems are reconstructed.

2.3. Drivers of eco-innovation
A recent literature review provides an analysis of the recurring eco-innovation themes in a corpus of 384 journal papers extracted from Scopus [1]. Driver, i.e. the motivation to develop eco-innovation, is the most represented theme. Various papers confirm the crucial importance of current and expected regulations to develop eco-innovations [4, 27, 28]. Hojnik and Ruzzier [4] identify regulations as the main factor for the different types of ecoinnovations (product, process, organization) in the whole design process, from their development to their diffusion. In line with this result, Horbach et al. [27] propose to analyze the determinants of ecoinnovations by types of environmental impacts. They also show that regulation seems an important driver for all environmental areas, except for material and energy reduction.

Neverthess, Triguero et al. [29] emphasize different drivers according to the type of eco-innovation. The supply chain seems to be a more important driver for process and organizational eco-innovations than for product eco-innovations. Market is a driver on eco-innovative products and organizational innovations, while cost-savings is significant for eco-innovative processes.

\subsection{Summary}

Eco-innovation is an approach whose outlines have been evolving for the last years. The evolution has been operated not only in terms of semantic but also in terms of scope, from products to services and organizations, and recently to the integration of business models. Scholars emphasize the systemic aspects of eco-innovation, making it hard to grab as an outcome (intentional of not) and as a method since it requires the mobilization of multiple domains of knowledge (engineering, management, environmental science). There still are missing links and methodical pillars to transform eco-innovation into a shared practice in academia and in industry. In this paper, the focus is made on a collective attempt, within the EcoSD network, to clarify and formalize the implications of eco-innovation along several investigations in multidisciplinary groups. Practices and reflections of partners of the network 
are presented in the next section.

\section{Research process}

This research results from a first series of works, performed through the development of $\mathrm{PhD}$ in various French institutions $[17,18,19]$. The preliminary works raised new eco-innovation challenges to be studied in a more collaborative context. exploratory analysis of two main one yearcollaborative research projects, concluded with a final seminar involving various actors from academia, industry and consultancy.

In total, 30 academics and industrials experts in ecodesign and/or eco-innovation have participated in the two collaborative research projects and about 70 to the final seminar.

The research methodology consists of an

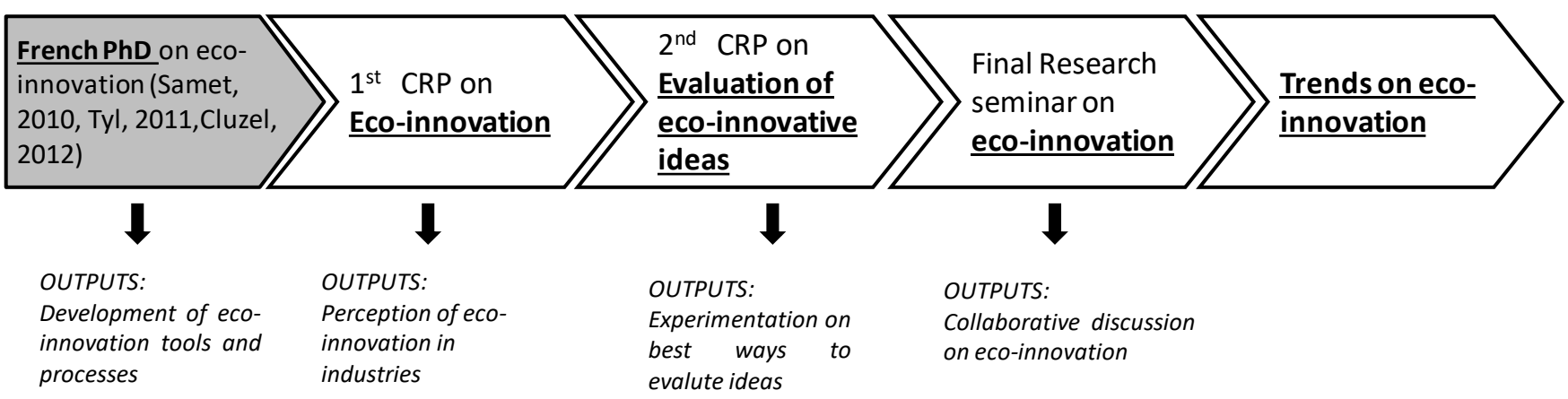

Figure 1 Eco-innovation research process

Figure 1 shows a schematic temporal overview of the research set-up.

A first collaborative research project (2012-2013) consisted in performing interviews to challenge the industrial perception of eco-innovation. A qualitative survey with French enterprises already involved in eco-design was conducted. Therefore, 12 French structures were involved through semistructured in-depth interviews. From these interviews, companies underlined the crucial role of ideas assessment during the eco-innovation process (see Box 1).

Consequently, a second collaborative research project (2013-2014) was deployed in order to understand how to perform the environmental evaluation of ideas in the early phases of the development process in a design team.

This second project mainly consisted in performing an experimental test, to map, select, combine ideas and perform the environmental evaluation of ideas on two case studies. The empirical setting involved 14 participants and 2 volunteering Master students.

This project underlined the need to develop new kind of business models to introduce in the market eco- innovative products and services. (see Box 2).

Each CRP started with an extensive state of the art and was coordinated in several meetings with all the stakeholders involved.

Finally gathering over 70 participants, a one-day final seminar was held in March 2015 after the closure of the projects in order to open first trends and perspectives in eco-innovation, through a particular focus on new sustainable business models.

All the data for this paper have been gathered from a preliminary state of art, interviews of industrials practitioners, as well as experimental tests, and also the conclusions drawn during the seminar.

\section{Main results from CRP1 and CRP2}

This paper exposes the main results and conclusions of each project. For more information, one can refer to the papers [30,31].

4.1. The industrial perception of eco-innovation

In this section four areas of interest are developed: definition of eco-innovation by partners; drivers to eco-innovation; types of projects and finally processes, methods and tools.

Is eco-innovation driven by innovation or environment? 
It has been detected that for most respondents, ecoinnovation is an "innovation driven by the need to decrease environmental impacts". Yet, for two companies of the sample, eco-innovation is rather "an eco-design process with a specific upstream creativity stage". Beyond a simple semantic difference, each vision is associated in practice with the internal organization of companies, and the physical anchoring of people supporting eco-innovation. It seems important to point out that eco-innovation either develops in innovation departments (in most reported cases), or more rarely in eco-design departments (when they exist).

Comparing eco-design and eco-innovation, goals appear to be similar through the survey. Companies are developing responses to triggers (also defined as drivers, see following paragraph) that may lead them to a serendipitous eco-innovation. This is indeed a hint to the non-intentional character of eco-innovation pinpointed in [21].

\section{What are the drivers identified by partners?}

Six broad categories of levers were identified in the survey: energetic and economic crises as a general framework; standardization; regulations (current and future); Corporate Social Responsibility (CSR); competitiveness; pressure of clients; health of consumers. Regulation dominates the responses of the industrial sample, in accordance with the observations of [4]. But this statement is mitigated by a surveyed consultant, who specifies that ecoinnovation goes beyond regulations and standard requirements, as it is meant to meet more stringent clients' expectations and to be more competitive. The comprehensive survey by [1] confirms the reported levers at a macro level for regulation; meso level (i.e. sector/market level) for market dynamics, including pressure of clients; micro level (i.e. enterprise level) for CSR. Yet health of the consumers, which is related to harmful or toxic substances for consumers in the automobile sector, does not clearly appear in [1].

What are the types of eco-innovation projects developed?

Reported eco-innovation projects on the field of mobility and energy sometimes imply the emergence of new technologies, but preferably foster innovations in the usage of products and in the development of new services and business models. In order to limit the risk due to technical shifts, existing technologies are preferably integrated and combined into a portfolio of eco-innovative offers (products and services). This is a first insight into the "unexplored realm of eco-innovation in service firms" mentioned in [1]. Development of services hence appeal to methods and business models to create sustainable value, as advocated in [7].

What are the eco-innovation processes, methods, and tools reported by partners?

No particular eco-innovation method or tool was mentioned by surveyed organizations, nor the existence of a structured eco-innovation process. Besides, Life Cycle Assessment and environmental accounting tools were put forward linked with an ecodesign practice, and creativity tools (such as TRIZ) were mentioned for innovation. This is logical considering the double belonging of eco-innovation to either eco-design or to innovation departments. More surprisingly it was made no reference to the ecoinnovation tools developed within the network itself (for instance [18]). Taking a step aside, responses may be different today given the increasing popularity of the Business Model Canvas [32], and its recent sustainable version, namely Triple Layered Business Model Canvas [33].

\section{Intermediary conclusions}

The questions derived from this survey are twofold. First, on a broad level there is evidence of a difficult transfer of academic eco-innovation research to industrial practices. This deserves more attention. Also, promotion of tools developed internally to the EcoSD network towards industrial partners should be improved, as it is not proved effective to date.

Secondly, it is suggested to investigate the development of eco-innovation process(es) in different industrial contexts, focusing on two central areas of interest. These are related to the generation of ideas (called eco-ideation, see [11, 12, 34]) and to the evaluation of the environmental potential of ideas [14]. The latter subject was tackled along the following collaborative project, whose main results are presented in next section. 
4.2. The performance of environmental evaluation of ideas

This study focused on the way the design teams turn between 14 and 15 elementary ideas (previously generated) into 1 to 3 concepts with a high environmental potential. Three methods were introduced and compared: Combineval based on idea combination; Geneval based on idea maturation, free method.

\section{Environmental evaluation of ideas}

Results from the workshop and from the environmental evaluation of the two datasets highlight a large intergroup variability whatever the method implemented. Indeed, few ideas shared the same environmental potential from one group to another. In addition a rank reversal is observed for several ideas. Two main reasons explain such a situation. First, the environmental assessment is sensitive to the set of indicators applied which is different from one method to another. Second, the format of ideas seems crucial for the interpretation and the (re-)appropriation of ideas by the evaluation group.

\section{Selected ideas and emerging concepts}

Among the 14 and 15 ideas, for the parkmeter and the crumpled paper respectively, more or less ideas were selected to be converted into promising concepts. As expected, the Combineval approach selected the highest number of ideas. The Geneval approach isolated less ideas with a lowest preliminary environmental potential to make them evolve towards final concepts with highest environmental potential than the sum of elementary ideas. A large overlap is also observed between Geneval and Combineval. Similar ideas are selected to define the final concepts. The main explanation is based on a system of values which is shared by the two methods. Finally, the control (free) method isolated the most promising ideas from the initial dataset to define the final concepts.

\section{Participants' feedbacks}

In a second part, participants' feedbacks were collected after the workshop. Qualitative answers were treated to assess the adhesion of participants to the methods, the influence of ideas maturity and the global perception of the eco-innovation process.

\section{Level of adhesion}

The level of adhesion evaluates the approval towards the ideas scoring and selection. The Control method (free) was perceived as the most performant followed by the Geneval approach and finally the Combineval method. Nevertheless, the type of case study was pointed out as a big issue. As an example, the Geneval approach failed to assess ideas related to the crumpled paper. Ideas and especially the format of ideas were judged as inadequate to be evaluated.

The control method presents the highest level of adhesion. However specific comments counterbalance this result. If the set of indicators is well scored by participant, the control group established its own indicators, the definition of the final concepts was subject to discussion and characterized by a loose consensus. Questions raised about the completeness of the dataset, the choice of relevant indicators and the multicriteria decision-making process (multiple and sometimes conflicting dimensions).

Finally, the eco-innovation process is perceived as being highly sensitive to the method employed. Methodical constraints and the ideas reappropriation are the most often cited issues.

\section{Evaluation of low maturity ideas}

Most of ideas were characterized as immature by the participants. This trend was especially observed for the second prospective case study (the crumpled paper). The lack of information often conduced the evaluation groups to provide their own interpretation of ideas, defining or redefining the scope, the object under study, the stakeholders involved or the usage situations. However, Geneval and Combineval approaches are perceived as more robust to ideas of low maturity since they make ideas evolve, mature finally combine them into innovative concepts. The influence of the format of ideas is again pointed out as a mean to reduce the perceived maturity of an idea. A single picture or few words written on a sheet of paper are perceived as insufficient to ensure the integrity of an idea. In these conditions the evaluation 
groups often fail while capturing the sense and context behind the elementary idea.

\section{Overall perception of the eco-evaluation process}

The global perception of the eco-evaluation process is good. The proposed process is widely accepted by most of the participants essentially because of its repeatability. It was also qualified as compatible with an early design phase.

The main drawback cited during the questionnaire is still the appropriation of ideas by the participants. A proposal to overcome the issue might be the inclusion of people who participated to the ideation process into the evaluation group. This inclusion might be a good solution to guarantee a shared vision of ideas among the evaluation group members.

\section{Trends and perspectives for eco- innovation research}

On the basis of these recent eco-innovation projects, three interlinked directions for research in ecoinnovation, in a process-based perspective, have been identified (Figure 2).

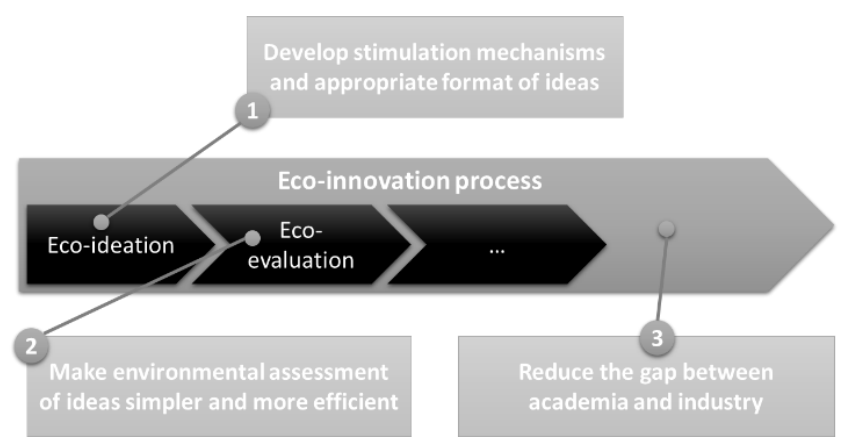

Figure 2. Overview of the main trends and perspectives in ecoinnovation

5.1 Eco-ideation: develop stimulation mechanisms and appropriate format of ideas

The first direction concerned the eco-ideation stage. Even if a lot of eco-ideation tools exist, none of them are used in French industry. They are judged too complicated or not adapted, or are simply not known by companies. A particular focus should thus be made on identifying the right eco-ideation tool in a given industrial context. Research should particularly consider developing easy-to-use tools based on all the dimensions of eco-innovation, but also improving and adapting existing tools to industrial context and use [34, 35].

In this perspective, instead of developing more ecoinnovation tools, appropriate stimulation mechanisms could be implemented into the ecoinnovation process to help the design team generate relevant ideas with a high potential of sustainability. The ambition is to provide the design team a systematic stimulation across all the dimensions of eco-innovation: through biomimicry, Product Service System, short and closed loop, etc. A first proposal of 8 mechanisms to stimulate eco-ideation has been developed [36]. There is a potential for a virtual and interactive exploration of eco-innovative ideas, as suggested in [3].

Finally, the format of ideas is infamously evoked as a crucial question and seems an interesting topic for future work. What should be the input (from the ecoideation stage) and the output (to feed the next steps) formats of an idea to preserve and transfer information during the eco-innovation process, and to help evaluation of ideas with a comparable level of detail for all ideas? Should this format be specific for eco-innovation by highlighting environmental or sustainable considerations? This is still an on-going question.

5.2 Eco-evaluation: make environmental assessment of ideas simpler and more efficient

The second direction is to make environmental assessment of ideas simpler and more efficient in early phases of an eco-innovation process. From the first works highlighted in this paper, the authors have identified the need to go further in the development of environmental evaluation methods and tools in order to:

- Improve and adapt to industrial contexts the existing eco-evaluation methods and tools;

- $\quad$ Test and validate them;

- Provide sufficient information to select and implement the most efficient approach in a given context.

Eco-evaluation has been relatively neglected by researchers, whereas it is a crucial phase necessary to a successful eco-innovation approach [14, 31]. 
Various questions remain open, some of them being clearly linked with the first direction (section 5.1): what is the adapted format of ideas? How to co-create environmental/sustainability criteria in project teams? How to adapt the method/tool to the context/product?

\subsection{Reduce the gap between academia and industry}

The last direction is to reduce the gap existing between academia and industry. With more efficient and improved methods and tools, the transfer of knowledge from academia to industry should be facilitated. However working on methods and tools is necessary but not sufficient. There is a need to go further with a more global approach of ecoinnovation. The authors particularly underline some promising paths to reduce this gap.

- The question of business models is essential, in order to market advantages of eco-innovation and give competitiveness to companies. This question already received a particular attention from researchers and has become a promising field of research $[7,8]$.

- Another essential aspect is to work closer with industry by improving and reinforcing collaborations. Eco-innovation methods and tools need to be permanently confronted with the industrial field to both be validated and diffused. French researchers have clearly good opportunities to foster these types of collaboration thanks to a favorable national research context (ANR projects, CIFRE thesis, industrial chairs...), that has been already used $[15,18$, $19,35]$ and needs to be pursued.

- Aligned with the previous proposals, the integration of eco-innovation methods and tools in existing eco-design or innovation processes and organizations is another important question that needs a renewed attention. Companies are often reluctant to revise their existing design processes. On one hand this aspect requires attention from researchers to provide acceptable insights for companies, and on the other hand it is also essential to highlight the advantages of eco-innovation to promote it and facilitate its industrial acceptability.

\subsection{International perspective}

O'Hare and McAloone identified ten opportunities for engineering design research in eco-innovation [22]. 1. A widely accepted typology of approaches to environmental product design;

2. A comprehensive and rigorous review of tools to support eco-innovation;

3. A guidance on when and where eco-innovation is relevant;

4. Collaborative researches at the interfaces;

5. Studies of eco-innovation implementation;

6. A greater reporting of case studies of failures;

7. Methodological innovation;

8. Bringing design thinking to business model innovation;

9. Understanding the role of LCA in supporting eco-innovative product development;

10. Development of an interface with policy research.

The research projects presented is this paper have been conducted independently and partially overlapping O'Hare and McAloone's recommendations leading to some shared conclusions. Opportunities 2, 3, 4, 5, 7 and 8 are in particular in total accordance with the authors' analysis based at the French level. So it is interesting to highlight that the conclusions emitted in a French context echo at an international level. The key to solve the research questions raised in these papers probably stand in a more collaborative research in eco-innovation at an international level. Such collaborations have already been initiated and should be reinforced in the forthcoming years.

\section{Conclusions}

The aim of this paper is to provide new insights in eco-innovation through a sequential research process composed of two collaborative research projects and a final seminar. The delivered insights are believed to be valuable to the interaction design and engineering community, with the aim to envision interactive ecoinnovation tools for instance.

First, a set of interviews of practitioners already involved in eco-design was carried out in order to apprehend the perception of eco-innovation by industries. Then an experimental test was developed to get information on the specific stage of evaluation 
of eco-innovative ideas.

The state of art in section 2 identified regulation as the main factor for the development of eco-innovations. But this research balances this result. We identified the importance to develop more efficient ways to generate and evaluate ideas as a major driver, as well as developing new sustainable business models.

Some limitations need to be acknowledged. The reduced sample of companies in CRP1 does not allow drawing any general conclusions. Moreover, the experimental test on the evaluation of ideas did not lead to significant differences. Nevertheless, the main challenge tackled in this test was more to identify how the participants were able to monitor the selection, environmental evaluation and maturation of ideas into concept thanks to a set of shared environmental/sustainability criteria adapted to the case.

Several perspectives may be considered. First, we need to develop national and international collaborative research projects in eco-innovation. Moreover, researchers must collaborate always closer with industry by co-developing methods, tools, processes or good practices and by identifying case studies and testing grounds in multiple sectors. To finish, we underline the need to share knowledge and experience with academia and industry through scientific publications and dedicated events like the 2015 EcoSD seminar "The challenges of eco-innovation: from eco-ideation toward sustainable business models" organized by the authors [37].

\section{Acknowledgements}

The authors would like to thank the French EcoSD network for its financial support to the Collaborative Research Projects between 2012 and 2014, and to the 2015 annual seminar. All the EcoSD participants to the projects are also thanked for their involvement.

\section{References}

[1] Díaz-García, C.; González-Moreno, Á.; Sáez-Martínez, F. J. Eco-innovation: insights from a literature review. Innovation 2015, 17(1), 6-23.

[2] Cherifi, A., Dubois, M., Gardoni M., Tairi A. Methodology for innovative eco-design based on TRIZ. Int. J. Inter. Des. Manuf. 2015, 9(3), 167-175.

[3] Xiaomin, L., Shuiping, H., Yuting, C. Research and application: conceptual integrated model based on TRIZ and bionics for product innovation. Int. J. Inter. Des. Manuf. 2016, $1-9$.

[4] Hojnik, J.; Ruzzier, M. What drives eco-innovation? A review of an emerging literature. Environ. Innovation Soc. Transitions 2015, in press

http://dx.doi.org/10.1016/j.eist.2015.09.006

[5] Carrillo-Hermosilla J.; del Rio P., Könnöla T. Ecoinnovation-When sustainability and competitiveness shake hands; Palgrave Macmillan: London, 2009.

[6] Carrillo-Hermosilla J.; del Rio P.; Könnöla T. Diversity of eco-innovations: Reflections from selected case-studies. $J$. Clean. Prod. 2010, 18 (10-11), 1073-1083.

[7] Bocken, N.; Short, S.; Rana, P.; Evans, S. A literature and practice review to develop sustainable business model archetypes, J. Clean. Prod. 2014, 65, 42-56.

[8] Boons, F.; Lüdeke-Freund, F. Business models for sustainable innovation: state-of-the-art and steps towards a research agenda, J. Clean. Prod. 2013, 45, 9-19.

[9] Hellström, T. Dimensions of environmentally sustainable innovation: the structure of eco - innovation concepts. Sustainable Development 2013, 15(3), 148-159.

[10] O'Hare J.A. Eco-innovation tools for the early stages: an industry-based investigation of tool customisation and introduction, PhD Thesis, University of Bath, UK, 2010.

[11] Tyl, B.; Legardeur, J.; Millet, D.; Vallet, F. A comparative study of ideation mechanisms used in eco-innovation tools. J. Eng. Design 2014, 25(10-12), 325-345.

[12] Bocken, N. M. P.; Allwood, J. M.; Willey, A. R.; King, J. M. $\mathrm{H}$. Development of an eco-ideation tool to identify stepwise greenhouse gas emissions reduction options for consumer goods. J. Clean. Prod. 2011, 19(12), 1279-1287.

[13] Bocken N.M.P.; Allwood J.M.; Willey A.R.;.King J.M.H. Development of a tool for rapidly assessing the implementation difficulty and emissions benefits of innovations, Technovation 2012, 32: 19-31.

[14] Vallet F.; Tyl B.; Millet D.; Eynard B. A method to select best nuggets from eco-innovation sessions. In Green Design, Materials and Manufacturing Processes, $\mathrm{H}$. Bartolo et al. (Eds), pp 647-654. CRC Press/Balkema, Leiden Netherlands, 2013.

[15] Real, M. Accompagner la maturation des concepts au sein des processus d'éco-innovation: proposition de la méthode MIRAS, pour aider à surmonter les fixations collectives et explorer les réseaux de parties prenantes, PhD Thesis , University of Bordeaux, Bordeaux, France, 2015

[16] EIO and CfSD. Eco-innovate! A guide to eco-innovation for SMEs and business coaches. Eco-Innovation Observatory. Funded by the European Commission, DG Environment, Brussels, 2013.

[17] Samet Kallel, W. Développement d'une méthode d'écoinnovation, PhD Thesis, Arts et Métiers ParisTech, Bordeaux, France, 2010.

[18] Tyl, B. L'apport de la créativité dans les processus d'écoinnovation - Proposition de l'outil EcoASIT pour favoriser l'éco-idéation de systèmes durables, $\mathrm{PhD}$ thesis, Université Bordeaux 1, Bordeaux, France, 2011.

[19] Cluzel, F. Mise en oeuvre de l'éco-conception pour des systèmes industriels complexes: de l'ACV par scénarios à la définition d'un portefeuille de projets de R\&D éco-innovants, $\mathrm{PhD}$ Thesis, Ecole centrale de Paris, Châtenay-Malabry, 2012.

[20] Fussler C.; James P. Driving Eco Innovation-A breakthrough 
discipline for innovation and sustainability. Pitman Publishing, Pearson Professional Ltd., 1996.

[21] Mathieu A.; Reynaud E.; Chandon J.L. ; Les déterminants internes de l'éco innovation : Analyse de 118 éco innovations selon le référentiel gestionnaire et la stratégie RSE de l'entreprise, [Online]. Finance Contrôle Stratégie 18-1 | 2015. http://fcs.revues.org/1592 (accessed Feb 12, 2016).

[22] O'Hare, J.A., McAloone, T.C., Eco-innovation: the opportunities for engineering design research, in: DS 77: Proceedings of the DESIGN 2014 13th International Design Conference. Dubrovnik, Croatia, 2014, pp. 1631-1640.

[23] O'Hare, J.A., McAloone, T.C., Pigosso, D.C.A., Howard, T.J., 2014. Eco-innovation Manual-Tools Instruction. United Nations Environment Programme/DTU.

[24] Rennings, K. Redefining innovation-eco-innovation research and the contribution from ecological economics. Ecol. Econ. 2000, 32(2), 319-332.

[25] Roscoe, S.; Cousins, P. D.; Lamming, R. C. Developing ecoinnovations: a three-stage typology of supply networks. $J$. Clean. Prod 2016, 112, 1948-1959.

[26] Hansen, E. G.; Grosse-Dunker, F.; Reichwald, R. Sustainability innovation cube - a framework to evaluate sustainability-oriented innovations. Int. J. Innovat. Tech. Manag. 2009, 13(04), 683-713.

[27] Horbach, J.; Rammer, C.; Rennings, K.. Determinants of eco-innovations by type of environmental impact-The role of regulatory push/pull, technology push and market pull. Ecol. Econ. 2012, 78, 112-122.

[28] Horbach, J. Empirical determinants of eco-innovation in European countries using the community innovation survey. Environ. Innovation Soc. Transitions 2015, in press, http://dx.doi.org/10.1016/j.eist.2015.09.005

[29] Triguero, A.; Moreno-Mondéjar, L.; Davia, M.A. Drivers of different types of eco-innovation in European SMEs, Ecol. Econ. 2013, 92, 25-33

[30] Cluzel F.; Vallet F.; Tyl B.; Bertoluci G.; Leroy Y.; Ecodesign vs eco-innovation: an industrial survey, International design conference - In: Proceedings of International Design Conference - Design 2014; Dubrovnik, Croatia, 2014.

[31] Leroy, Y.; Tyl, B.; Vallet, F.; Cluzel, F. Environmental evaluation of ideas in early phases: a challenging issue for design teams. In The 20th International Conference on Engineering Design (ICED 15), Vol. 1, pp. 117-126.

[32] Osterwalder, A.; Pigneur, Y. Business Model Generation: a Handbook for Visionaries, Game changers and Challengers; John Wiley and Sons: Hoboken, New Jersey, 2010.

[33] Joyce. A.; Paquin, R.; Pigneur, Y. The triple layered business model canvas: a tool to design more sustainable business models. In: Proceedings of ARTEM Organizational Creativity International Conference, Nancy, France, 26-27, 2015.

[34] Cluzel, F.; Yannou, B.; Millet, D.; Leroy, Y. Eco-ideation and eco-selection of R\&D projects portfolio in complex systems industries. J. Clean. Prod. 112, 2016, 4329-4343.

[35] Saidani, M., Cluzel, F., Leroy, Y., Auclaire, A. Timeefficient eco-innovation workshop process in complex systems industries. In: Proceedings of International Design Conference - Design 2016; Dubrovnik, Croatia, 2016.

[36] Tyl, B., Vallet, F., Pialot, O., Millet, D., Le Duigou, J., Graves, G. The ESM approach: 8 mechanisms to efficiently support eco-ideation. In: Proceedings of International Design Conference - Design 2016. Presented at the
International Design Conference - Design 2016, Dubrovnik, Croatia, 2016.

[37] Cluzel, F., Tyl, B., Vallet, F. (coord.). The challenges of ecoinnovation - From eco-ideation toward sustainable business models. EcoSD Annual Workshop 2015. Presses des Mines, In press 


\section{The industrial perception of eco-innovation}

CRP1 was launched in 2012 to elaborate the perception of eco-innovation by French organizations in confrontation of existing body of literature. The panel of surveyed organizations are large companies, consultancies, an association and a technical centre involved for several years in ecodesign approaches and projects.

Features of the research method were defined as follows (adapted from (Blessing and Chakrabarti, 2009).

- Research questions: How is eco-innovation perceived and defined in reference to ecodesign by French industrial practitioners? What are the expected outcomes of ecoinnovation? Has the organization already experienced eco-innovation projects?

- Nature: Industrial survey

- Theoretical bases: Other industrial surveys [Santolaria et al., 2011; Bocken et al., 2014]

- Unit of analysis: Perception of eco-innovation in French multi-sectorial organizations committed to eco-design

- Setting: In-house (i.e. in vivo, in organization facilities)

- Participants: 18 volunteering industrial partners

- Case: 12 semi-structured in-depth interviews (1 to 3 respondents per organization)

- Data collection: Audio-recording

- Data analysis: Transcription without coding and qualitative analysis

- Verification: Confrontation with literature

- Duration: 30 to 90 -minute interviews

- Main findings: (1) Boundary between eco-design and eco-innovation are blurred;

(2) Eco-innovation is not supported by a structured process;

(3) Surveyed organizations do not take advantage of eco-innovation methods and tools developed in academia.

Box 1 Main information concerning CRP 1 


\section{The performance of environmental evaluation of ideas}

CRP2 was launched in 2013. Following the results from the CRP1, the focus was made on early design phases, e.g. ideation and concept generation. The main purpose was to address the way the design teams turn elementary ideas into concepts with a high environmental potential. To do so, three methods (free, Geneval and Combineval) were tested on two different case studies (the parkmeter and the crumpled paper). 14 participants from different various technical background assessed, selected and combined elementary ideas into promising ecofriendly concepts. Features of the research method are adapted from (Blessing and Chakrabarti, 2009).

- Research questions: How to turn elementary ideas into concepts with a high environmental potential in a design team? What is the influence of the method on the selected ideas and emerging concepts?

- Nature :

Comparative test

- Theoretical bases:

Literature review

- Unit of analysis:

Influence of selection, combination and maturation methods of ideas on environmental potential

- Setting:

In vitro, in a test room

- Participants:

14 participants from EcoSD French network (industrial, consultants, academics and students)

- Case: 2 test cases providing elementary ideas, a parking meter (14 ideas) and future uses of crumpled paper (15 ideas)

- Data collection: Documents, questionnaires, empirical notes

- Data analysis: Qualitative and quantitative analysis

- Duration: One-day workshop, two 2-hour sessions

- Main findings: (1) A large intergroup variability is observed during the evaluation of ideas whatever the method employed

(2) Most promising ideas were captured through the implementation of Geneval and Combineval approaches

(3) Geneval and Combineval approaches are less impacted by a low maturity level of ideas

(4) The process of idea evaluation and selection is highly sensitive to the format of ideas. 